Article

\title{
Analysis of Systemic Inflammatory Factors and Survival Outcomes in Endometrial Cancer Patients Staged I-III FIGO and Treated with Postoperative External Radiotherapy
}

\author{
Katarzyna Holub ${ }^{1,2, *}$, Fabio Busato ${ }^{2}$, Sebastien Gouy ${ }^{3}$, Roger Sun ${ }^{2}{ }^{\circledR}$, Patricia Pautier ${ }^{4}$, \\ Catherine Genestie ${ }^{5}$, Philippe Morice ${ }^{3}$, Alexandra Leary ${ }^{4}$, Eric Deutsch ${ }^{2}$, \\ Christine Haie-Meder ${ }^{2}$, Albert Biete ${ }^{1}$ and Cyrus Chargari ${ }^{2}$ \\ 1 Radiation Oncology Department, Hospital Clinic de Barcelona, University of Barcelona, \\ 08036 Barcelona, Spain; abiete@clinic.cat \\ 2 Radiotherapy Department, Gustave Roussy Cancer Campus, 94800 Villejuif, France; \\ fabiobusato2004@libero.it (F.B.); roger.sun@gustaveroussy.fr (R.S.); Eric.DEUTSCH@gustaveroussy.fr (E.D.); \\ christine.haiemeder@gustaveroussy.fr (C.H.-M.); cyrus.chargari@gustaveroussy.fr (C.C.) \\ 3 Surgery Department, Gustave Roussy Cancer Campus, 94800 Villejuif, France; \\ sebastien.gouy@gustaveroussy.fr (S.G.); philippe.morice@gustaveroussy.fr (P.M.) \\ 4 Medical Oncology Department, Gustave Roussy Cancer Campus, 94800 Villejuif, France; \\ patricia.pautier@gustaveroussy.fr (P.P.); Alexandra.LEARY@gustaveroussy.fr (A.L.) \\ 5 Pathology Department, Gustave Roussy Cancer Campus, 94800 Villejuif, France; \\ catherine.genestie@gustaveroussy.fr \\ * Correspondence: holub@clinic.cat; Tel.: +34-6679-74255
}

Received: 27 February 2020; Accepted: 31 March 2020; Published: 12 May 2020

\begin{abstract}
Background: The causal link between elevated systemic inflammation biomarkers and poor survival has been demonstrated in cancer patients. However, the evidence for this correlation in endometrial cancer (EC) is too weak to influence current criteria of risk assessment. Here, we examined the role of inflammatory indicators as a tool to identify EC patients at higher risk of death in a retrospective observational study. Methods: A total of 155 patients surgically diagnosed with EC stage I-III FIGO 2009 and treated with postoperative External Beam Radiotherapy (EBRT) \pm brachytherapy and chemotherapy according to ESMO-ESTRO-ESGO recommendation for patients at high risk of recurrence at the Gustave Roussy Institut, France, and Hospital Clínic, Spain, between 2008 and 2017 were evaluated. The impact of pre-treatment Neutrophil-to-Lymphocyte Ratio (NLR $\geq 2.2$ ), Monocyte-to-Lymphocyte Ratio (MLR $\geq 0.18$ ), Systemic Immune-Inflammatory Index (SII $\geq 1100$ ) and lymphopenia $\left(<1.0 \times 10^{9} / \mathrm{L}\right)$ on overall survival (OS), cancer-specific survival and progression-free survival was evaluated. Subsequently, a cohort of 142 patients within high-advanced risk groups according to ESMO-ESGO-ESTRO classification was evaluated. Results: On univariate analysis, NLR (HR = 2.2, IC 95\% 1.1-4.7), SII (HR = 2.2, IC 95\% 1.1-4.6), MLR (HR = 5.0, IC 95\% 1.1-20.8) and lymphopenia (HR = 3.8, IC 95\% 1.6-9.0) were associated with decreased OS. On multivariate analysis, NLR, MLR, SII and lymphopenia proved to be independent unfavorable prognostic factors. Conclusions: lymphopenia and lymphocytes-related ratio are associated with poorer outcome in surgically staged I-III FIGO EC patients classified as high risk and treated with adjuvant EBRT and could be considered at cancer diagnosis. External validation in an independent cohort is required before implementation for patients' stratification.
\end{abstract}

Keywords: endometrial cancer; systemic inflammation; neutrophil-to-lymphocytes ratio (NLR); systemic immune-inflammatory index (SII); monocyte-to-lymphocyte ratio (MLR); lymphopenia 


\section{Introduction}

Endometrial cancer (EC) is the most common malignancy of the female reproductive system in developed countries and the only gynecological cancer with a rising incidence $(+1.3 \%$ per year over the last 10 years) and mortality rate [1,2]. It is estimated that in 2020, 65,620 new patients will be diagnosed, and 12,590 women will die of this disease in the United States [1]. Although the average 5 -year survival is high $(95.0 \%)$ when the disease is confined to the uterus, it is substantially lower in the presence of regional or distant dissemination [2,3].

The assessment of EC recurrence risk relies on the consensus of the European Society for Medical Oncology (ESMO), the European Society for Radiotherapy \& Oncology (ESTRO) and the European Society of Gynecological Oncology (ESGO), which standardized EC primary treatment choice by using traditionally applied tumor-related risk factors such as tumor grade, histology, clinical and radiological stage according to the International Federation of Gynecology and Obstetrics (FIGO) and lymphovascular invasion [4]. However, there is growing evidence that the outcome of EC patients may also depend on factors beyond the classically established risk indicators mentioned above $[5,6]$. Up to now, the only attempts to refine the ESMO-ESGO-ESTRO risk assessment have been directed towards surgical nodal staging, and new prognostic tools beyond this classification are warranted in order to identify women with a higher risk of death [7]. The role of a host's inflammatory response in cancer progression has been the topic of numerous research articles published in the last years, which analysed the level of inflammatory ratios based on blood components, such as Neutrophil-to-Lymphocytes Ratio (NLR), Platelet-to-Lymphocytes Ratio (PLR), Monocyte-to-Lymphocytes Ratio (MLR) or Systemic Immune-Inflammation Index (SII) as useful prognostic factors in different malignancies [7-16]. Nevertheless, in the case of EC, there is insufficient evidence to support their use in clinical practice, as shown by Ethier et al. in an extensive review of 26 studies with a total of 10,530 patients with different gynecological cancers published in 2017, where EC was depicted only in two studies with less than 1000 patients [17-19]. Moreover, none of these inflammatory biomarkers have so far been proposed to refine the ESMO-ESGO-ESTRO EC risk assessment [17-24].

Our research aims to provide new data about the suitability of inflammatory biomarkers as indicators of EC prognosis.

\section{Patients and Methods}

\subsection{Patients' Inclusion Criteria}

The institutional databases of patients with histologically proven EC, surgically staged as FIGO I-III and treated between February 2008 and January 2017 with postoperative External Beam Radiotherapy (EBRT), were retrospectively reviewed. The study protocol was approved by our Institutional Review Boards (the Gustave Roussy Multidisciplinary Board for Gynecological Cancer and the Ethical Committee of Hospital Clinic de Barcelona with project identification code: Hb_endometri) and was conducted in accordance with ethical standards following the rules of the Declaration of Helsinki (https://www.wma.net/what-we-do/medical-ethics/declaration-of-helsinki/), revised in 2013.

The clinical data of women with high-intermediate risk, high risk, or advanced uterine endometrial cancer (according to ESMO-ESGO-ESTRO risk stratification) and with accessible results of blood test done within 3 months prior to surgery were selected and retrospectively examined in two European institutions. All patients underwent hysterectomy with bilateral adnexectomy and pelvic and/or para-aortic lymphadenectomy according to individual staging requirements. The indication of postoperative adjuvant treatment was applied according to the ESMO guidelines [4]. Patients diagnosed with uterine sarcomas, acute or chronic infections (including Human Immunodeficiency Virus and virus of hepatitis), immunodeficiency, other active malignancies, hematological disorders, patients treated with therapies causing immunomodulation (such as steroid or anti-inflammatory drugs), patients not treated with adjuvant EBRT or patients with metastatic disease were excluded. A flowchart for patients' exclusion is shown in Supplementary Figure S1. 


\subsection{Inflammatory Indicators}

The following preoperative inflammatory indicators were examined: Neutrophil-to-Lymphocyte ratio (NLR: neutrophil count divided by the lymphocyte count), Systemic Immune inflammation Index (SII: neutrophil count multiplied by platelets count and divided by the lymphocyte count) and Monocyte-to-Lymphocyte ratio (MLR: monocyte count divided by the lymphocyte count).

From the entire cohort, the most appropriate cut-off value for each indicator was chosen, according to the optimal decision threshold from the receiver operating characteristics (ROC) curve. The main endpoint of our research was to examine overall survival (OS) and cancer-specific survival (CSS) of the entire cohort stratified according to the level of inflammatory factors. The impact of inflammatory factors on Progression Free Survival (PFS) was also assessed. In addition, biological ratios were examined for correlations with age, FIGO stage, tumor grade and histology.

\subsection{Follow-Up and Statistical Analysis}

Follow-up (FU) was performed as a clinical exam every 3-4 months for the first 2 years, and then every 6 months for the next 3 years (with radiological exams guided by symptoms), following ESMO guidelines [4]. All statistical tests were two-sided and $p$-value $<0.05$ was considered as statistically significant. All examined factors were defined as binary variables, by finding the cut-off value from a ROC curve, and their balance across prognostic characteristics was assessed using Chi-square test $\left(\mathrm{X}^{2}\right)$. Frequencies were compared using Fisher's exact test for categorical variables. Statistical significance was calculated by Student's $t$ test when comparing two groups, or by one-way or two-way ANOVA when comparing three or more. Survival outcomes were calculated from the date of surgery (first treatment) to the event occurrence, which was the death by any cause for OS and the cancer-related death for CSS. Progression-Free-Survival was calculated from the date of surgery to the disease progression or cancer-related death. Patients were censored if no event occurred. Survival curves for different types of survival measures were constructed via the Kaplan-Meier method and comparisons were made using the Wald test. For univariate and multivariate analyses of prognostic variables, Cox proportional hazards regression was applied and the variables with $p$-value $<0.10$ in Cox univariate analysis were analysed in multivariate analysis. All statistical analyses were performed using standard software (SPSS v 23.00; SPSS Inc., Chicago, IL, USA).

\section{Results}

\subsection{Patients and Tumors}

A total of 155 women (77 patients in Gustave Roussy Cancer Center and 78 patients in Hospital Clinic de Barcelona) were eligible for inclusion in the study. The median age at diagnosis was 63.1 years (range 27.9-98.9 years). The most frequent histology was endometrioid carcinoma (61.3\%). After surgery, the disease stage was classified according to the FIGO 2009 as stage I-II in 97 patients $(62.6 \%)$ and stage III in 58 cases (37.4\%). High tumor grade (grade 3 ) was present in 96 patients $(61.9 \%)$. Lymphadenectomy was performed in 129 patients (83.2\%), pelvic in 30 patients $(19.4 \%)$, paraaortic in 21 patients $(13.5 \%)$, and both in 78 patients $(50.3 \%)$. Out of the remaining 26 patients $(16.8 \%), 13$ were classified within a high-intermediate risk group 3, 9 showed a negative result of sentinel lymph node procedure and in 4 cases these data were missing. According to ESMO-ESGO-ESTRO risk groups, 13 patients $(8.4 \%)$ had high-intermediate risk cancer, 134 (86.5\%) had high-risk disease, and eight $(5.2 \%)$ had advanced stage. Patients' demographics and characteristics of tumours for each center and for the entire cohort are detailed in Supplementary Table S1.

\subsection{Treatments}

All patients were treated with postoperative EBRT (mean dose was $45.4 \mathrm{~Gy}$ ). A High-Dose Rate Brachytherapy boost (HDR-BT) was administered to 145 patients (93.5\%) with a mean dose of 10 Gy for HDR-BT, 10 patients (6.2\%) received exclusive EBRT (mean dose 45 Gy). A total of 
78 patients $(50.3 \%)$ also received adjuvant chemotherapy (CT), mostly cisplatin-based (40 patients) for 4-6 cycles, carboplatin-taxol (34 patients), carboplatin (1 patient), cisplatin-paclitaxel (1 patient), cisplatin-doxorubicine (2 patients).

\subsection{Outcome}

Median FU of the entire cohort was 46.5 months (range 4.0-108.0). Forty patients (25.8\%) had died at the time of data collection, 35 of these deaths were cancer-related $(22.6 \%)$. In the entire study population, 3- and 5-years OS rates were $81.0 \%$ and $73.0 \%$ respectively. Forty-seven patients $(30.3 \%)$ presented disease recurrence, with median time from surgery to cancer progression of 13.0 months (range 0.7-72.5). In details, sites of recurrence were as follows: four patients presented only local (vaginal) progression, five patients had exclusively pelvic nodal progression, six patients had both local and pelvic progression, four patients had local and distant failure, eight patients had pelvic and distant progression and 20 patients had exclusively distant progression.

\subsection{Systemic Inflammation Markers: Cut-Off Value}

The most appropriate cut-off value for each indicator was as follows: 2.2 for NLR, with an area under curve (AUC) of 0.641 , a sensitivity (Se) of 0.8 and a specificity (Sp) of 0.4 . The optimal cut-off value for SII was 1100.0 (AUC 0.540, Se 0.4, Sp 0.7) and 0.2 for MLR (AUC 0.541, Se 0.7, Sp 0.5). A high pre-treatment NLR $\geq 2.2$ was observed in 93 patients (60.0\%), SII $\geq 1100$ in 30 patients (19.4\%), MLR $\geq 0.18$ in 125 patients $(80.6 \%)$, and lymphopenia in 11 patients $(7.1 \%)$. Additionally, a high level of monocytes $\left(\geq 0.8 \times 10^{9} / \mathrm{L}\right)$ and platelets $\left(\geq 410 \times 10^{9} / \mathrm{L}\right)$ were detected in $7(4.5 \%)$ and 8 patients $(5.2 \%)$, respectively. Strong correlations were observed between all immune parameters $(p<0.001)$ in the Spearman's test. Neutrophils count was not significant ( $p=0.972$ for a cut-off value at $7 \mathrm{G} / \mathrm{L}$ ).

\subsection{Survival Analysis}

Prognostic factors in Kaplan-Meier survival analysis; univariate cox regression is shown in Table 1. Univariate analyses showed an increased risk of death in patients with high NLR (HR $=2.2$, IC 95\% 1.1-4.7), high SII (HR = 2.2, IC 95\% 1.1-4.6), high MLR (HR = 5.0, IC 95\% 1.1-20.8) and lymphopenia (HR $=3.8$, IC 95\% 1.6-9.0). Of note, age, FIGO stage III, tumor grade 3 and non-endometrioid histology did not reach statistical significance. CT use had no impact on mOS $(p=0.614)$ in Kaplan-Meier analysis, with $24.4 \%$ deaths in CT cohort vs. $27.3 \%$ in non-CT cohort. Regarding the possible influence of age on inflammatory factors, we did not observe any significant impact of age $<50$ and age $<55$ on mOS ( $p=0.350$ and $p=0.812$ ), nor any significant correlation with levels of NLR, SII, MLR or lymphopenia. Menopausal status was not available, and could therefore not be tested accurately.

Given the correlation between parameters, separate multivariate analyzes were done for each factor. On multivariate analysis for OS, the following variables were independent factors for OS: NLR, MLR, SII and lymphocytes count (Table 1). The effect of inflammatory markers on OS is shown in Figure 1. The same analysis for CSS revealed similar results for FIGO stage III, MLR and lymphopenia (Table 2). The effect of inflammatory markers on CSS is shown in Figure 2. Regarding PFS, only FIGO stage III and pre-treatment lymphopenia were statistically significant (Table 3). 

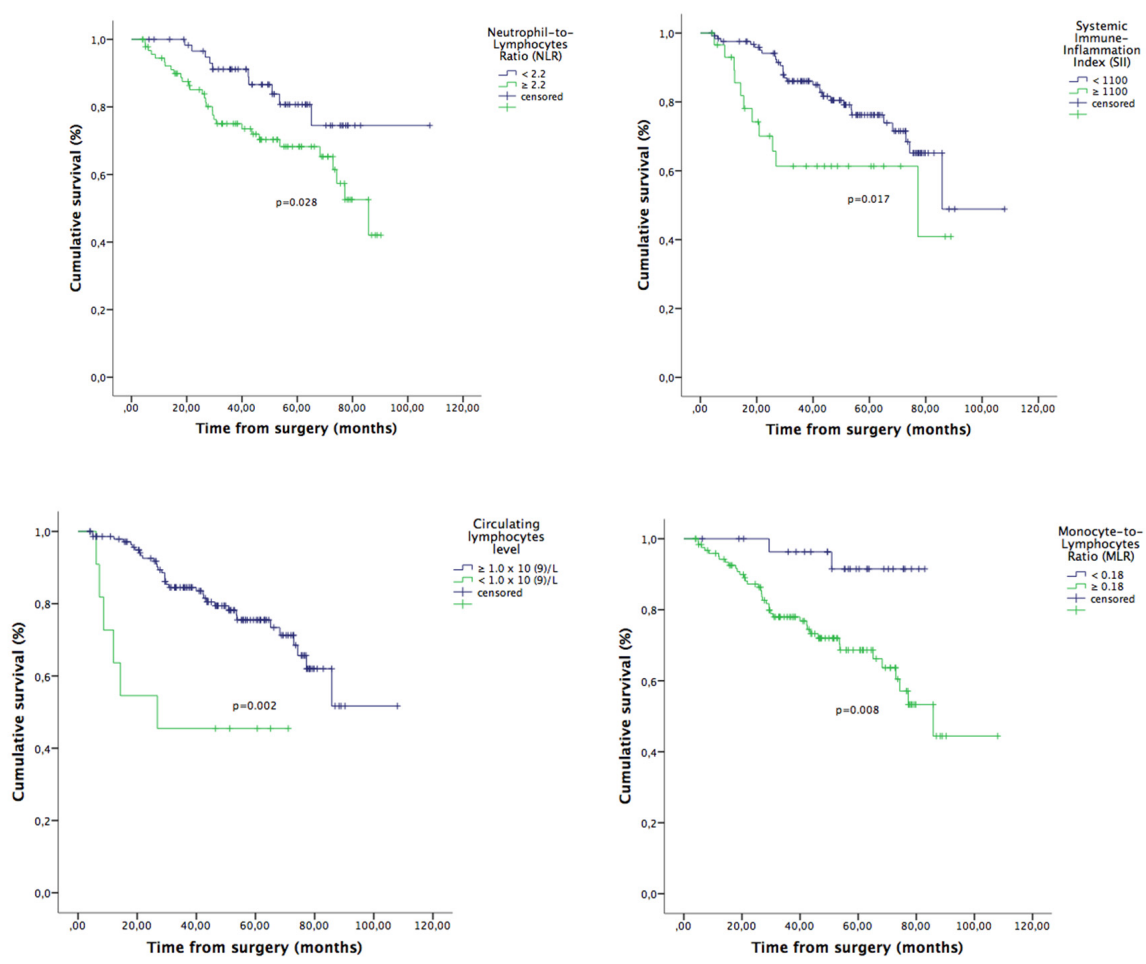

Figure 1. Overall survival in all patients included $(n=155)$ : Impact of pre-treatment Neutrophil-to-Lymphocyte (NLR; cut-off $\geq 2.2$ ), Systemic Immune-Inflammatory Index (SII; $\geq 1100)$, Monocyte-to-Lymphocyte Ratio (MLR; $\geq 0.18)$, and circulating lymphocytes $\left(<1.0 \times 10^{9} / \mathrm{L}\right)$ on overall survival (OS) of the endometrial cancer (EC) patients.
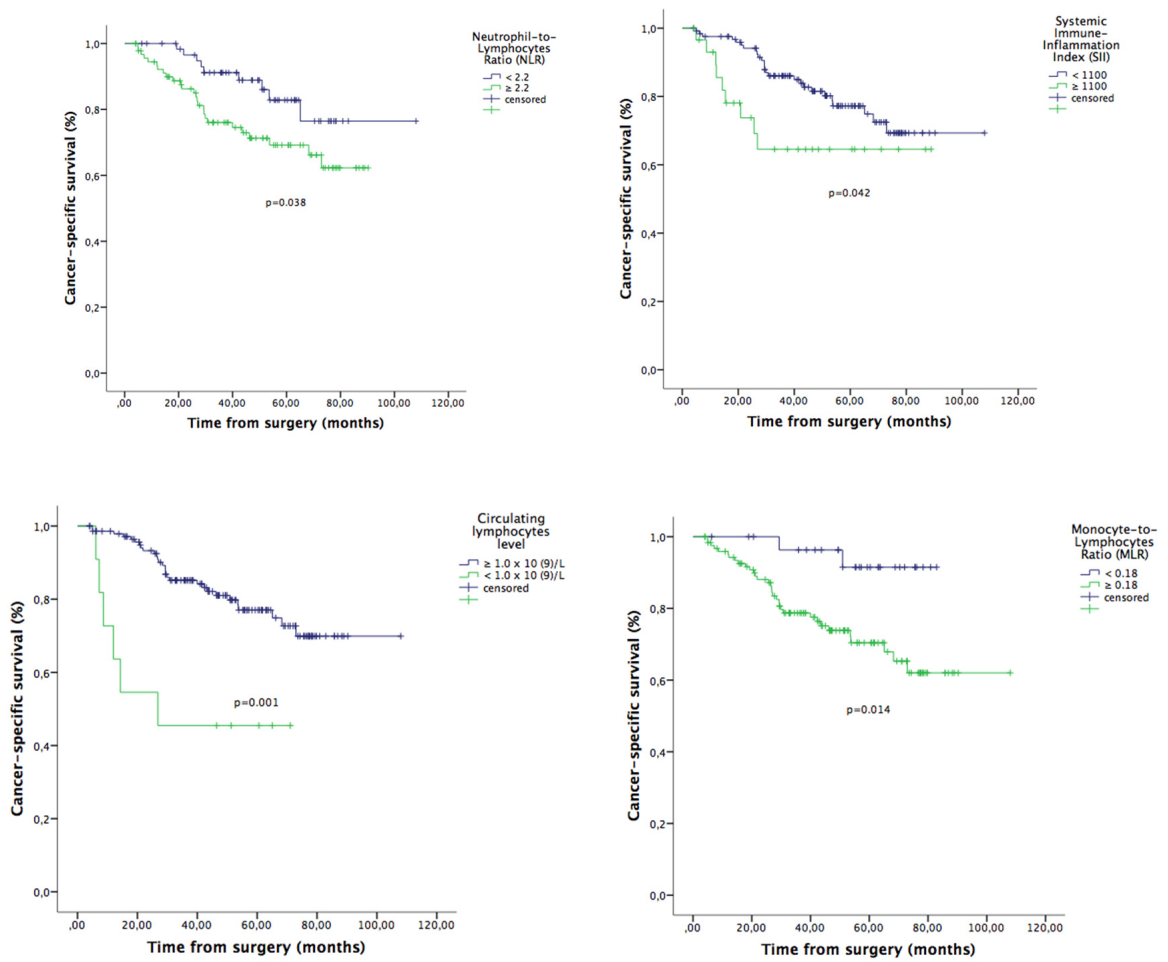

Figure 2. Cancer-specific survival in all patients included $(n=155)$ : Impact of pre-treatment Neutrophil-to-Lymphocyte (NLR; cut-off $\geq 2.2$ ), Systemic Immune-Inflammatory Index (SII $\geq 1100$ ), Monocyte-to-Lymphocyte Ratio (MLR; $\geq 0.18$ ), and circulating lymphocytes $\left(<1.0 \times 10^{9} / \mathrm{L}\right)$ on cancer-specific survival (CSS) of the of the endometrial cancer (EC) patients. 
Table 1. Overall survival analysis $(n=155)$.

\begin{tabular}{|c|c|c|c|c|c|c|c|}
\hline \multirow{2}{*}{$\begin{array}{l}\text { OS, } n=155 \\
\text { Variables }(n)\end{array}$} & \multicolumn{3}{|c|}{ Kaplan-Meier Survival Analysis } & \multicolumn{2}{|c|}{ UNIVARIATE Cox Regression } & \multicolumn{2}{|c|}{ MULTIVARIATE Cox Regression } \\
\hline & $\mathrm{X}^{2}$ & $p$-Value & OS (Range) & HR (IC 95\%) & $p$-Value & HR (IC 95\%) & $p$-Value \\
\hline Age $\geq 65$ years (vs. $<65$ years) & 0.9 & 0.343 & 67.5 (58.9-76.1) vs. $78.0(65.9-90.1)$ & $1.6(0.8-3.1)$ & 0.171 & - & - \\
\hline FIGO stage III (vs. stage I-II) & 2.1 & 0.150 & $72.9(67.4-78.4)$ vs. $78.0(66.8-89.3)$ & $1.6(0.8-2.9)$ & 0.153 & - & - \\
\hline Tumor grade 3 (vs. grade $1-2$ ) & 2.1 & 0.145 & $67.6(61.1-74.1)$ vs. 85.7 (75.6-95.9) & $1.6(0.8-3.3)$ & 0.210 & - & - \\
\hline Endometrioid histology (vs. other histology) & 0.0 & 0.869 & $80.3(71.2-89.4)$ vs. $69.5(61.6-77.5)$ & $0.9(0.4-1.7)$ & 0.656 & - & - \\
\hline $\begin{array}{l}\text { NLR } \geq 2.2 \\
\text { (vs. }<2.2)\end{array}$ & 4.8 & 0.028 & $66.4(59.6-73.2)$ vs. $91.7(82.5-100.9)$ & $2.2(1.1-4.7)$ & 0.043 & $2.3(1.1-4.6)$ & 0.027 \\
\hline $\begin{array}{l}\mathrm{SII} \geq 1100 \\
\text { (vs. }<1100)\end{array}$ & 5.6 & 0.017 & 58.5 (44.9-72.1) vs. 82.3 (73.5-91.2) & $2.2(1.1-4.6)$ & 0.047 & $2.3(1.2-4.7)$ & 0.017 \\
\hline $\begin{array}{l}\text { MLR } \geq 0.18 \\
\text { (vs. }<0.18)\end{array}$ & 7.1 & 0.008 & $75.4(67.2-83.6)$ vs. $79.4(74.7-84.1)$ & $5.0(1.1-20.8)$ & 0.027 & $5.9(1.4-24.6)$ & 0.015 \\
\hline $\begin{array}{l}\text { Lymphocytes } \\
<1.0 \text { (vs. } \geq 1.0 \text { ) }\end{array}$ & 10.0 & 0.002 & 39.1 (21.6-56.6) vs. $82.1(74.5-89.7)$ & $3.8(1.6-9.0)$ & 0.003 & $4.3(1.8-10.7)$ & 0.001 \\
\hline
\end{tabular}

OS: overall survival, $\mathrm{X}^{2}$ : Chi-square test, HR: Hazard Ratio, IC: confidence interval, FIGO: International Federation of Gynecology and Obstetrics, NLR: Neutrophil-to-Lymphocytes ratio, SII: Systemic Immune-Inflammatory Index, MLR: Monocyte-to-Lymphocyte ratio).

Table 2. Cancer-specific survival analysis $(n=155)$.

\begin{tabular}{|c|c|c|c|c|c|c|c|}
\hline \multirow{2}{*}{$\begin{array}{l}\text { CSS, } n=155 \\
\text { Variables }\end{array}$} & \multicolumn{3}{|c|}{$\begin{array}{l}\text { Kaplan-Meier Survival Analysis, } \\
\text { CSS, } n=155 \text { Patients }\end{array}$} & \multicolumn{2}{|c|}{ UNIVARIATE Cox Regression } & \multicolumn{2}{|c|}{ MULTIVARIATE Cox Regression } \\
\hline & $\mathrm{X}^{2}$ & $p$-Value & CSS (Range) & HR (IC 95\%) & $p$-Value & HR (IC 95\%) & $p$-Value \\
\hline Age $\geq 65$ years (vs. $<65$ years) & 1.9 & 0.167 & $68.5(60.0-77.0)$ vs. $89.5(82.2-96.9)$ & $1.4(0.8-2.5)$ & 0.206 & - & - \\
\hline FIGO stage III (vs. stage I-II) * & 4.5 & 0.034 & $78.0(66.8-89.3)$ vs. $75.7(70.4-81.1)$ & $2.0(1.04-3.9)$ & 0.038 & $2.2(1.1-4.3)$ & 0.021 \\
\hline Tumor grade $3($ vs. grade $1-2)$ & 1.6 & 0.206 & 69.8 (63.3-76.3) vs. 89.4 (79.7-99.1) & $1.1(0.6-2.1)$ & 0.648 & - & - \\
\hline Endometrioid histology (vs. other histology) & 0.2 & 0.656 & $86.2(78.1-94.3)$ vs. $70.1(62.9-78.9)$ & $0.8(0.4-1.4)$ & 0.391 & - & - \\
\hline $\begin{array}{l}\mathrm{NLR} \geq 2.2 \\
(\text { vs. }<2.2)\end{array}$ & 4.3 & 0.038 & $68.9(62.0-75.7)$ vs. $93.0(84.0-102.1)$ & $1.4(0.8-2.5)$ & 0.285 & - & - \\
\hline $\begin{aligned} & \mathrm{SII} \geq 1100 \\
&\text { (vs. }<1100)\end{aligned}$ & 4.1 & 0.042 & $63.2(49.5-76.9)$ vs. 87.7 (80.9-94.5) & $1.4(0.7-2.7)$ & 0.352 & - & - \\
\hline $\begin{array}{c}\text { MLR } \geq 0.18 \\
(\text { vs. }<0.18)\end{array}$ & 6.0 & 0.014 & 60.5 (47.0-74.1) vs. $79.4(74.7-88.6)$ & $4.9(1.2-20.8)$ & 0.027 & $5.4(1.3-22.7)$ & 0.020 \\
\hline $\begin{array}{l}\text { Lymphocytes } \\
<1.0 \text { (vs. } \geq 1.0 \text { ) }\end{array}$ & 11.1 & 0.001 & $39.2(21.7-56.6)$ vs. $87.6(81.2-94.1)$ & $4.0(1.7-9.7)$ & 0.002 & $5.0(2.0-12.5)$ & 0.001 \\
\hline
\end{tabular}

* FIGO stage III in separate Cox multivariate models: HR = 2.4 (IC 95\% 1.2-4.7, $p=0.014$ ) for lymphopenia. CSS: cancer-specific survival, $\mathrm{X}^{2}$ : Chi-square test, HR: Hazard Ratio, IC: confidence interval, FIGO: International Federation of Gynecology and Obstetrics, NLR: Neutrophil-to-Lymphocytes ratio, SII: Systemic Immune-Inflammatory Index, MLR: Monocyte-to-Lymphocyte ratio. 
Table 3. Progression-specific survival analysis $(n=155)$.

\begin{tabular}{|c|c|c|c|c|c|c|c|}
\hline \multirow{2}{*}{$\begin{array}{l}\text { PFS, } n=155 \\
\text { Variables }\end{array}$} & \multicolumn{3}{|c|}{ Kaplan-Meier Survival Analysis } & \multicolumn{2}{|c|}{ UNIVARIATE Cox Regression } & \multicolumn{2}{|c|}{ MULTIVARIATE Cox Regression } \\
\hline & $\mathrm{X}^{2}$ & $p$-Value & PFS (Range) & HR (IC 95\%) & $p$-Value & HR (IC 95\%) & $p$-Value \\
\hline Age $\geq 65$ years (vs. $<65$ years) & 2.3 & 0.128 & $65.7(59.3-72.1)$ vs. $61.9(51.4-72.4)$ & $1.4(0.8-2.5)$ & 0.206 & - & - \\
\hline FIGO stage III (vs. stage I-II) & 11.4 & 0.001 & $71.3(65.1-77.5)$ vs. $54.9(44.3-65.5)$ & $2.3(1.3-4.1)$ & 0.004 & $2.4(1.4-4.3)$ & 0.002 \\
\hline Tumor grade 3 (vs. grade $1-2$ ) & 0.2 & 0.650 & $67.2(59.3-75.0)$ vs. $66.3(57.2-75.3)$ & $1.1(0.6-2.1)$ & 0.648 & - & - \\
\hline Endometrioid histology (vs. other histology) & 0.3 & 0.574 & $66.5(59.1-73.8)$ vs. $66.5(59.1-73.8)$ & $0.8(0.4-1.4)$ & 0.391 & - & - \\
\hline $\begin{array}{l}\mathrm{NLR} \geq 2.2 \\
(\text { vs. }<2.2)\end{array}$ & 0.7 & 0.409 & $62.3(54.7-69.8)$ vs. $68.5(58.9-78.2)$ & $1.4(0.8-2.5)$ & 0.709 & - & - \\
\hline $\begin{array}{c}\text { SII } \geq 1100 \\
\text { (vs. }<1100)\end{array}$ & 1.7 & 0.192 & $67.6(60.8-74.3)$ vs. $55.6(41.6-69.6)$ & $1.4(0.7-2.7)$ & 0.719 & - & - \\
\hline $\begin{array}{l}\text { MLR } \geq 0.18 \\
(\text { vs. }<0.18)\end{array}$ & 3.0 & 0.083 & $77.7(65.8-89.7)$ vs. 60.7 (54.3-67.1) & $2.2(0.9-5.1)$ & 0.080 & - & - \\
\hline $\begin{array}{l}\text { Lymphocytes } \\
<1.0 \text { (vs. } \geq 1.0 \text { ) }\end{array}$ & 4.6 & 0.033 & $67.5(61.3-73.8)$ vs. $37.2(18.9-55.5)$ & $2.4(1.1-5.6)$ & 0.049 & $2.7(1.1-6.4)$ & 0.024 \\
\hline
\end{tabular}

PFS: progression-free survival, $X^{2}$ : Chi-square test, HR: Hazard Ratio, IC: confidence interval, FIGO: International Federation of Gynecology and Obstetrics, NLR: Neutrophil-to-Lymphocytes ratio, SII: Systemic Immune-Inflammatory Index, MLR: Monocyte-to-Lymphocyte ratio. 


\section{Discussion}

The impact of systemic inflammation on cancer development has attracted a great deal of attention over the last years [7-11,14]. The analysis of the hematological inflammatory indicators and their ability to serve as possible prognostic factors has been investigated in several malignant tumours [12,13,15-24]. These new prognostic indicators are warranted to refine the prognosis and guide adjuvant treatments because the survival outcomes of patients treated according to the guidelines based only on tumor characteristics may differ widely among patients classified within the same group of risk. We observed through the survival analysis, that a high pre-treatment NLR, SII, MLR and a low lymphocytes count were associated with a worse OS for EC patients surgically staged as FIGO I-III and who received adjuvant EBRT. Due to the correlation existing between all inflammatory factors, the multivariate analysis model was evaluated separately for each immune factor studied. NLR, SII, MLR, and lymphocytes count were significant for OS.

These data are in line with other recently published results in the literature. Dong et al. reviewed clinical records of 510 Chinese EC patients surgically treated between 2010-2016 and found that NLR was an independent prognostic marker for OS (HR 4.7; 95\% CI, 1.5-14.1; $p=0.006$ ), CSS (HR 3.6; 95\% CI, 1.1-11.5; $p=0.028$ ) and disease free survival (DFS, HR 2.3; 95\% CI, 1.0-5.2; $p=0.044$ ) [25]. Based on the data of 101 patients, Mirili et al. confirmed that NLR $>3.3$ and PLR $>177$ were associated with shorter PFS and OS, and were the first to prove that SII $>1035.9$ and prognostic nutritional index $(\mathrm{PNI})<38$ were also independent prognostic factors for worse survival outcomes in EC. The authors also examined a correlation between inflammatory factors and classically used prognosticators such as lymph node involvement, FIGO stage, lymphovascular invasion, and cervical stromal invasion, which they found that were associated with higher NLR, SII, and lower PNI. Moreover, NLR and PNI were associated with ECOG performance scores 2-3 and myometrial invasion [26]. Similarly, a recent Japanese study on 197 EC patients identified a high NLR and PLR as predictive of lymph node involvement, observed in 25 patients (13\%) [27]. Acikgoz et al. reported that the preoperative NLR $>2.41$ was a significant predictor for cervical stromal involvement in endometrioid endometrial adenocarcinoma $(p=0.006$, $\mathrm{OR}=2.03$ ) [20]. In an article based on the retrospective data of 320 patients, Hannuma et al. confirmed that pre-treatment NLR was an independent predictor of poor prognosis in EC (HR 3.3; 95\% CI 1.2-9.5; $p=0.026$ ) [18]. In a systematic review of eleven studies, elevated NLR was related with advanced stage of disease in EC patients [28]. Regarding the impact of inflammatory indices on time from surgery to disease progression, only lymphopenia at cancer diagnosis and FIGO stage III were significantly associated with poorer PFS. This may be related with the fact that 11 patients who had progression during follow-up were classified as disease-free after salvage treatment of recurrence with RT \pm BT. These findings may also explain that among studies investigating the impact of inflammatory markers on EC survival outcomes, all focus on OS and very few investigated impacts on PFS [17-19].

The strength of our study in comparison with previously reported publications relies on its bi-institutional cohort of high-risk patients, all of them treated with EBRT. Until now, the only multicenter study with a larger cohort than ours, with 605 patients, was published by Cummings et al., but only $33 \%$ were treated with radiotherapy. Cummings et al. also included patients in FIGO stage IV [17], while all our patients were staged as FIGO I-III but classified within the ESMO-ESGO ESTRO 3-5 groups. For this reason, patients treated with exclusive HRD-BT did not meet inclusion criteria, as in accordance with the guidelines published by ESMO-ESGO-ESTRO in 2015, only patients belonging to the high-intermediate, high and advanced risk group should be treated with postoperative adjuvant $\mathrm{EBRT} \pm \mathrm{BT}$ (patients with low and intermediate risk of recurrence were excluded from the study) [4].

Regarding the cut-off values, the applied thresholds vary widely among studies, as there are no clinically obvious cut-points. For example, Cummings demonstrated that NLR $\geq 2.4$, but not MLR $\geq 0.19$ had independent prognostic significance for OS and CCS [17]. We applied similar cut-off values (NLR $\geq 2.2$, MLR $\geq 0.18$ ) based on the ROC curves for OS in our population. Although this method is not free of potential bias (overestimation of the effect), the ROC curve analysis is nowadays applied in the majority of studies on inflammatory ratios $[19,26,29]$. Moreover, for NLR, which is 
the most frequently studied ratio, our thresholds are similar to the cut-points found in the general population and match the upper limits of physiological values published by Fest et al. based on data of more than 8700 healthy subjects [30].

The classically applied variables in our study such as histology (endometrioid vs. others) and tumor grade (grade 3 vs. grade 1-2) did not achieve statistical significance in univariate Cox regression. We assume that adjuvant treatments may have alleviated the effects of such clinical features by decreasing their intrinsic prognostic value. Moreover, all our patients belong to the high-risk cohort (ESMO-ESGO-ESTRO 3-5 group), where these classical parameters should not be analysed separately but as a sum of characteristics. For example, the tumor grade 3 is a stronger prognosticator of more aggressive evolution than FIGO stage or histology [4].

The lymphocyte count was the most significant parameter for survival. Given the fact that lymphocyte count is part of all indexes, we may hypothesize that lymphopenia could be the most robust biomarker among all tested factors, that all are depending on lymphocytes count. In line with this, only the significance of lymphocytes count remained if indexes cutoff were not chosen from ROC curves, but instead based on a value used in daily routine. Interestingly, we however observed that the percentage of patients showing a high level of blood test components (established according to values in our laboratory: neutrophilia $\geq 7.0$, monocytosis $\geq 0.8$, thrombocytosis $\geq 410$ or lymphopenia $<1.0)$ was relatively low $(11.6 \%, 4.5 \%, 5.2 \%$ and $7.1 \%$ of patients, respectively) and does not explain the high number of patients with elevated corresponding inflammation markers (high NLR in $60.0 \%$, high MLR in $80.6 \%$ and high SII in $19.4 \%$ respectively). In particular, the prevalence of neutrophilia at diagnosis was much lower, as compared to previous cohorts of patients with locally advanced squamous cell carcinoma (e.g., cervix, head and neck, anal carcinoma), where neutrophilia was reported in around $25 \%$ of cases and was found to be a major prognostic factor [31-37]. In this study, neutrophilia was not significant for survival. In a larger series of 508 patients, Takahashi et al. showed the prognostic significance of systemic neutrophil in surgically treated endometrial cancer patients. Indeed, neutrophilia was detected in $8.3 \%$ of patients at the time of the initial diagnosis and was found to be significantly associated with an advanced clinical stage, LVSI, and shorter survival. In details, neutrophilia was present in $5.3 \%, 11.1 \%, 10.6 \%$, and $41.2 \%$ of the patients with stage I, stage II, stage III and IV disease, respectively [38]. These results are in line with our data, as $62.6 \%$ of our patients were diagnosed in FIGO stage I-II disease. The absence of significance in our series may be consecutive to a selection of a rather homogeneous cohort without stage IV patients. This lower incidence of neutrophilia at diagnosis, as compared with squamous cell carcinoma, may be explained by different biologies. In addition to the fact that EC tumors are usually less necrotic tumors than cervical cancer (therefore leading to less systemic inflammation), we may hypothesize that the immunomodulating effect of inflammatory indices in EC patients may be seen not only as a consequence of a high or low level of their components, but possibly as depending on the interaction between the levels of different circulating blood cells. This interaction may influence the tumor microenvironment towards the conditions favorable for cancer development or suppression. This information may provide some rationale for use of the immunotherapy treatments, given the possible influence of the tumor microenvironment on the immune checkpoint inhibitors [39,40].

We assume limitations of our work, such as its retrospective nature, although almost all studies dealing with the systemic inflammation indicators are also retrospective [16-29]. As a bi-center project, some slight differences regarding the radiotherapy schedules between the two centers were admitted, but they did not seem to influence the survival outcomes. Most of the patients included $(91.6 \%)$ belonged to the high-risk group, as a consequence of inclusion criteria. Unfortunately, we did not have the records of patients' weight and height for the majority of Spanish patients, and therefore we were unable to assess the relationship between the Body Mass Index (BMI) and inflammatory factors. We also had some difficulties in accessing the results of the blood test at cancer diagnosis, as the majority of the patients were operated in their local centers then referred for adjuvant treatment in our comprehensive cancer centers. Furthermore, it would have been methodologically stronger to assess 
the effect of ratios in one cohort, then validate in another. Such analyses were done, but significance was not reached, possibly because of a low number of patients.

Taking into consideration these limitations, this study is the first describing such a high number of inflammatory indicators in the same rather homogenously treated multicenter cohort of $155 \mathrm{EC}$ patients. We observed that a high level of NLR, MLR and lymphopenia were associated with poorer outcome in EC and these findings are in accordance with previous similar studies [20-27]. There is still much uncertainty about how to select patients with EC who may benefit from treatment intensification. The most convincing evidence from the PORTEC 3 trial concerns stage III patients and the data generated here suggest that immune parameters may also be relevant for decision-making process. Nevertheless, the immune indicators should be verified in further prospective larger studies in order to confirm the cut-off points of immune indicators before moving into widespread clinical use. Furthermore, the validation of inflammatory factors in correlation with molecular diagnosis of EC should be done. Given the demonstrated value of molecular patterns in endometrial cancer (p53 mutation, POLE I mutational analysis, mismatch repair deficiency), next step will be to assess how inflammatory indicators may be used to refine patients prognosis and/or guide adjuvant therapies based on a molecular risk classification [41]. Especially for endometrial cancer with microsatellite instability (found in approximately $30 \%$ of all cases), which are histologically characterized by presence of tumor-infiltrating lymphocytes and high immunogenicity and are particularly appropriate for immunotherapy [42]. Unfortunately, MSI status was not available for analysis in our study (which is another limitation) but should be examined further with focus on inflammatory ratio and lymphocytes count for potential correlations.

\section{Conclusions}

Pre-treatment inflammatory indicators (NLR $\geq 2.2$, SII $\geq 1100$, MLR $\geq 0.18$ and lymphopenia) were found associated with worse survival outcome in high-risk EC patients surgically staged as I-III FIGO and treated with adjuvant EBRT. Among those, the lymphocyte count appeared as the most significant parameter. All these parameters are of interest but further research in larger cohort is required. Our study outlines the clinical importance of host-derived factors regulating the systemic inflammatory response in high-risk EC patients, and suggests implementation of this information for developing new therapeutic approaches and follow-up recommendations. Prospective external validation in an independent cohort is however required before implementing these indicators in patients risk stratification.

Supplementary Materials: The following are available online at http://www.mdpi.com/2077-0383/9/5/1441/s1: Table S1: Characteristics of patients and tumors; Figure S1: Exclusions flowchart $(n=155)$.

Author Contributions: Conceptualization: K.H. and C.C.; methodology: K.H. and C.C.; software, K.H., R.S.; validation: C.C., E.D., A.L., S.G., P.P., P.M., C.H.-M., A.B., F.B., C.G.; formal analysis: K.H., R.S.; investigation: K.H., C.G. and F.B.; resources: C.C., E.D., A.L., S.G., P.P., P.M., C.H.-M., C.G. and A.B.; data curation: K.H.; writing-original draft preparation, K.H., C.C.; writing-review and editing, C.C., A.L., R.S. and E.D.; visualization: K.H., C.C., E.D.; supervision: C.C., A.L., E.D., S.G., P.P., P.M., C.G. and C.H.-M.; project administration: C.C., K.H.; funding acquisition C.C. and K.H. All authors have read and agreed to the published version of the manuscript.

Funding: K.H. received travel grant from the University of Barcelona in order to work at the IGR on this project. This research received no other external funding.

Acknowledgments: We thank our colleagues from the Institute Gustave Roussy who provided insight and expertise that greatly assisted the research.

Conflicts of Interest: C.C. reports personal fees from MSD, personal fees from GSK, personal fees from Elekta, grants from Roche, non-financial support from TherAguIX, outside the submitted work. E.D. reports grants and personal fees from ROCHE GENENTECH, grants from SERVIER, grants from ASTRAZENECA, grants and personal fees from MERCK SERONO, grants from BMS, grants from MSD, outside the submitted work. A.L. reports grants, personal fees and non-financial support from AZ, grants, personal fees and non-financial support from Tesaro, grants, personal fees and non-financial support from clovis, grants and personal fees from MSD, personal fees from biocad, grants and personal fees from ability, outside the submitted work. R.S. reports non-financial support from AstraZeneca, outside the submitted work. P.M. reports personal fees from Roche, personal fees from AstraZeneca, personal fees from Johnson \& Johnson, personal fees from Clovis, outside the 
submitted work. K.H. reports grant from Universitat de Barcelona, during the conduct of the study. The remaining authors have nothing to disclose.

\section{References}

1. National Cancer Institute. SEER Stat Fact Sheets: Endometrial Cancer. Available online: http://seer.cancer. gov/statfacts/html/corp.html (accessed on 25 February 2020).

2. Siegel, R.L.; Miller, K.D.; Jemal, A. Cancer statistics, 2020. CA Cancer J. Clin. 2020, 70, 7-30. [CrossRef] [PubMed]

3. Pecorelli, S. Revised FIGO staging for carcinoma of vulva, cervix and endometrium. Int. J. Gynaecol. Obstet. 2009, 105, 103-104. [CrossRef] [PubMed]

4. Colombo, N.; Creutzberg, C.; Amant, F.; Bosse, T.; González-Martín, A.; Ledermann, J.; Marth, C.; Nout, R.; Querleu, D.; Mirza, M.; et al. ESMO-ESGO-ESTRO Endometrial Consensus Conference Working Group. ESMO-ESGO-ESTRO consensus conference on endometrial cancer: Diagnosis, treatment and follow-up. Radiother. Oncol. 2015, 117, 559-581. [CrossRef] [PubMed]

5. Suarez, A.A.; Felix, A.S.; Cohn, D.E. Bokhman redux: Endometrial cancer "types" in the 21st century. Gynecol Oncol. 2017, 144, 243-249. [CrossRef] [PubMed]

6. Arend, R.; Jones, B.; Martinez, A.; Goodfellow, P. Endometrial cancer: Molecular markers and management of advanced stage disease. Gynecol. Oncol. 2018, 150, 569-580. [CrossRef] [PubMed]

7. Ouldamer, L.; Bendifallah, S.; Body, G.; Canlorbe, G.; Touboul, C.; Graesslin, O.; Raimond, E.; Collinet, P.; Coutant, C.; Lavoué, V.; et al. Call for Surgical Nodal Staging in Women with ESMO/ESGO/ESTRO High-Intermediate Risk Endometrial Cancer: A Multicentre Cohort analysis from the FRANCOGYN Study Group. Ann. Surg. Oncol. 2017, 24, 1660-1666. [CrossRef]

8. Grivennikov, S.I.; Greten, F.R.; Karin, M. Immunity, inflammation, and cancer. Cell 2010, 140, $883-899$. [CrossRef]

9. Dolan, R.D.; Lim, J.E.K.; McSorley, S.T.; Horgan, P.G.; McMillan, D.C. The role of systemic inflammatory response in predicting outcomes in patients with operable cancer: Systematic review and meta-analysis. Sci. Rep. 2017, 7, 16717. [CrossRef]

10. Dupré, A.; Malik, H.Z. Inflammation and cancer: What a surgical oncologist should know. Eur. J. Surg. Oncol. 2018, 44, 566-570. [CrossRef]

11. Mantovani, A.; Allavena, P.; Sica, A.; Balkwill, F. Cancer-related inflammation. Nature 2008, 454, 436-444. [CrossRef]

12. Templeton, A.J.; Ace, O.; McNamara, M.G.; Al-Mubarak, M.; Vera-Badillo, F.E.; Hermanns, T.; Eruga, B.; Ocaña, A.; Tannock, I.F.; Amir, E. Prognostic role of platelet to lymphocyte ratio in solid tumours: A systematic review and meta-analysis. Cancer Epidemiol. Biomark. Prev. 2014, 23, 1204-1212. [CrossRef] [PubMed]

13. Templeton, A.J.; McNamara, M.G.; Šeruga, B.; Vera-Badillo, F.E.; Aneja, P.; Ocaña, A.; Leibowitz-Amit, R.; Sonpavde, G.; Knox, J.J.; Tran, B.; et al. Prognostic role of neutrophil-to-lymphocyte ratio in solid tumours: A systematic review and meta-analysis. J. Natl. Cancer Inst. 2014, 106, dju124. [CrossRef] [PubMed]

14. Candido, J.; Hagemann, T. Cancer-related inflammation. J. Clin. Immunol. 2013, 33 (Suppl. 1), S79-S84. [CrossRef]

15. Zhong, J.H.; Huang, D.H.; Chen, Z.Y. Prognostic role of systemic immune-inflamation index in solid tumours: A systemic review and meta-analysis. Oncotarget 2017, 8, 75381-75388. [CrossRef] [PubMed]

16. Guthrie, G.; Charles, K.A.; Roxburgh, C.S.; Horgan, P.G.; McMillan, D.C.; Clarke, S.J. The systemic inflammation-based neutrophil-lymphocyte ratio: Experiance in patients with cancer. Crit. Rev. Oncol. Hematol. 2013, 88, 218-230. [CrossRef]

17. Cummings, M.; Merone, L.; Keeble, C.; Burland, L.; Grzelinski, M.; Sutton, K.; Begum, N.; Thacoor, A.; Green, B.; Sarveswaran, J.; et al. Preoperative neutrophil: Lymphocyte and platelet: Lymphocyte ratios predict endometrial cancer survival. Br. J. Cancer 2015, 113, 311-320. [CrossRef]

18. Haruma, T.; Nakamura, K.; Nishida, T.; Ogawa, C.; Kusumoto, T.; Seki, N.; Hiramatsu, Y. Pre-treatment neutrophil to lymphocyte ratio is a predictor of prognosis in endometrial cancer. Anticancer Res. 2015, 35, 337-343. 
19. Ethier, J.L.; Desautels, D.N.; Templeton, A.J.; Oza, A.; Amir, E.; Lheureux, S. Is the neutrophil-to-lymphocyte ratio prognostic of survival outcomes in gynaecologic cancers? A systematic review and meta-analysis. Gynecol. Oncol. 2017, 145, 584-594. [CrossRef]

20. Acikgoz, A.S.; Cakmak, B.; Tuten, A.; Oncul, M.; Eskalen, S.; Demirkiran, F.; Arvas, M.; Guralp, O. Can preoperative neutrophil to lymphocyte and platelet to lymphocyte ratio predict cervical involvment in endometrioid endometrial adenocarcinoma? Eur. J. Gynaecol. Oncol. 2017, 38, 20-24.

21. Machida, H.; De Zoysa, M.Y.; Takiuchi, T.; Hom, M.S.; Tierney, K.E.; Matsuo, K. Significance of monocyte counts at recurrence on survival outcome of women with endometrial cancer. Int. J. Gynecol. Cancer 2017, 27, 302-310. [CrossRef]

22. Takahashi, R.; Mabuchi, S.; Kuroda, H.; Kozasa, K.; Yokoi, E.; Matsumoto, Y.; Kimura, T. The significance of pretreatment thrombocytosis and its association with neutrophilia in patients with surgically treated endometrial cancer. Int. J. Gynecol. Cancer 2017, 27, 1399-1407. [CrossRef] [PubMed]

23. Matsuo, K.; Hom, M.S.; Moeini, A.; Machida, H.; Takeshima, N.; Roman, L.D.; Sood, A.K. Significance of monocyte counts on tumour characteristics and survival outcome of women with endometrial cancer. Gynecol. Oncol. 2015, 138, 332-338. [CrossRef] [PubMed]

24. Menczer, J. Preoperative elevated platelet count and thrombocytosis in gynecologic malignancies. Arch. Gynecol. Obstet. 2017, 295, 9-15. [CrossRef]

25. Dong, Y.; Yuan, C.; Jianliu, W. The ratio of neutrophil to lymphocyte is a predictor in endometrial cancer. Open Life Sci. 2019, 14, 110-118. [CrossRef]

26. Mirili, C.; Bilici, M. Inflammatory prognostic markers in endometrial carcinoma: Systemic immune-inflammation index and prognostic nutritional index. Med. Sci. Discov. 2020, 7, 351-359. [CrossRef]

27. Aoyama, T.; Takano, M.; Miyamoto, M.; Yoshikawa, T.; Kato, K.; Sakamoto, T.; Takasaki, K.; Matsuura, H.; Soyama, H.; Hirata, J.; et al. Pretreatment Neutrophil-to-Lymphocyte Ratio Was a Predictor of Lymph Node Metastasis in Endometrial Cancer Patients. Oncology 2019, 96, 259-267. [CrossRef]

28. Pergialiotis, V.; Oikonomou, M.; Damaskou, V.; Kalantzis, D.; Chrelias, C.; Tsantes, A.E.; Panayiotides, I. Platelet to lymphocyte and neutrophil to lymphocyte ratio as predictive indices of endometrial carcinoma: Findings from a retrospective series of patients and meta-analysis. J. Gynecol. Obstet. Hum. Reprod. 2018, 47, 511-516. [CrossRef]

29. Eo, W.K.; Kwon, S.; Koh, S.B.; Kim, M.J.; Ji, Y.I.; Lee, J.Y.; Suh, D.S.; Kim, K.H.; Kim, H.Y. The Lymphocyte-Monocyte Ratio predicts patients survival and aggressiveness of endometrial cancer. J. Cancer 2016, 7, 538-545. [CrossRef]

30. Fest, J.; Ruiter, R.; Ikram, M.A.; Voortman, T.; Van Eijck, C.H.J.; Stricker, B.H. Reference values for white blood-cell-based inflammatory markers in the Rotterdam Study: A population-based prospective cohort study. Sci. Rep. 2018, 8, 10566. [CrossRef]

31. Schernberg, A.; Blanchard, P.; Chargari, C.; Ou, D.; Levy, A.; Gorphe, P.; Breuskin, I.; Atallah, S.; Caula, A.; Escande, A.; et al. Leukocytosis, prognosis biomarker in locally advanced head and neck cancer patients after chemoradiotherapy. Clin. Transl. Radiat. Oncol. 2018, 12, 8-15. [CrossRef]

32. Schernberg, A.; Reuze, S.; Orlhac, F.; Buvat, I.; Dercle, L.; Sun, R.; Limkin, E.J.; Escande, A.; Haie-Meder, C.; Deutsch, E.; et al. A score combining baseline neutrophilia and primary tumor SUVpeak measured from FDG PET is associated with outcome in locally advanced cervical cancer. Eur. J. Nucl. Med. Mol. Imaging 2018, 45, 187-195. [CrossRef] [PubMed]

33. Schernberg, A.; Blanchard, P.; Chargari, C.; Deutsch, E. Neutrophils, a candidate biomarker and target for radiation therapy? Acta Oncol. 2017, 56, 1522-1530. [CrossRef] [PubMed]

34. Schernberg, A.; Huguet, F.; Moureau-Zabotto, L.; Chargari, C.; Del Campo, E.R.; Schlienger, M.; Escande, A.; Touboul, E.; Deutsch, E. External validation of leukocytosis and neutrophilia as a prognostic marker in anal carcinoma treated with definitive chemoradiation. Radiother. Oncol. 2017, 124, 110-117. [CrossRef] [PubMed]

35. Schernberg, A.; Moureau-Zabotto, L.; Del Campo, E.R.; Escande, A.; Ducreux, M.; Nguyen, F.; Goere, D.; Chargari, C.; Deutsch, E. Leukocytosis and neutrophilia predict outcome in locally advanced esophageal cancer treated with definitive chemoradiation. Oncotarget 2017, 8, 11579-11588. [CrossRef]

36. Schernberg, A.; Escande, A.; Del Campo, E.R.; Ducreux, M.; Nguyen, F.; Goere, D.; Chargari, C.; Deutsch, E. Leukocytosis and neutrophilia predicts outcome in anal cancer. Radiother. Oncol. 2017, 122, 137-145. [CrossRef] 
37. Escande, A.; Haie-Meder, C.; Maroun, P.; Gouy, S.; Mazeron, R.; Leroy, T.; Bentivegna, E.; Morice, P.; Deutsch, E.; Chargari, C. Neutrophilia in locally advanced cervical cancer: A novel biomarker for image-guided adaptive brachytherapy? Oncotarget 2016, 7, 74886-74894. [CrossRef]

38. Takahashi, R.; Mabuchi, S.; Kawano, M.; Sasano, T.; Matsumoto, Y.; Kuroda, H.; Hisamatsu, T.; Kozasa, K.; Sawada, K.; Hamasaki, T.; et al. Prognostic significance of systemic neutrophil and leukocyte alterations in surgically treated endometrial cancer patients: A mono-institutional study. Gynecol. Oncol. 2015, 137, 112-118. [CrossRef]

39. Heong, V.; Ngoi, N.; Tan, D.S. Update on immune checkpoint inhibitors in gynecological cancers. J. Gynecol. Oncol. 2017, 28, e20. [CrossRef]

40. Sacdalan, D.; Lucerno, J.; Sacdalan, D. Prognostic utility of baseline neutrophil-to-lymphocyte ratio in patients receiving immune checkpoint inhibitors: A review and meta-analysis. Onco Targets Ther. 2018, 11, 955-965. [CrossRef]

41. Bosse, T.; Nout, R.A.; McAlpine, J.N.; McConechy, M.K.; Britton, H.; Hussein, Y.; Gonzalez, C.; Ganesan, R.; Steele, J.C.; Harrison, B.T.; et al. Molecular Classification of Grade 3 Endometrioid Endometrial Cancers Identifies Distinct Prognostic Subgroups. Am. J. Surg. Pathol. 2018, 42, 561-568. [CrossRef]

42. Karamurzin, Y.; Rutgers, J.K. DNA mismatch repair deficiency in endometrial carcinoma. Int. J. Gynecol. Pathol. 2009, 28, 239-255. [CrossRef] [PubMed]

(C) 2020 by the authors. Licensee MDPI, Basel, Switzerland. This article is an open access article distributed under the terms and conditions of the Creative Commons Attribution (CC BY) license (http://creativecommons.org/licenses/by/4.0/). 